\title{
PELATIHAN PUBLIC SPEAKING DAN DIGITAL MARKETING DI MASA PANDEMIC COVID-19 PADA KOMUNITAS IX PONDOK AREN TANGERANG SELATAN
}

\author{
Aris Ariyanto ${ }^{1}$, Aan Purnama ${ }^{2}$ Agus Sudarsono $^{3}$, Kiki Dwi Wijayanti ${ }^{4}$, \\ Mada Faisal ${ }^{5}$ \\ Universitas Pamulang \\ Email: dosen02492@unpam.ac.id
}

\begin{abstract}
Learning public speaking and digital marketing can be done by anyone, especially millennials who want to develop their skills, skills and personal development. Including a community. A good community must be able to increase the ability and independence of existing resources, that is, where a community must be able to produce a breakthrough for both its members and for the community group. The community must be able to generate benefits both financial and non-financial. Financial gain must be initiated by a business or business even if it is small. That is what encourages us to carry out community service activities to the ARIMBIN IX community. This activity aims to provide skills training for members of the nature-loving community so that they are able to communicate well, have confidence when appearing in public and provide provision for members of the nature-loving community to do entrepreneurship through digital marketing during the Covid-19 pandemic. The methods that will be used in achieving goals are various methods such as lectures, discussions, practice and question and answer, as well as regular community mentoring. This program has longterm results and goals based on several forms of service, namely creating a productive community for both the organization and its members both during the pandemic and in the future.
\end{abstract}

Keywords: Public speaking, digital marketing, community, pandemic, covid-19

\begin{abstract}
Abstrak
Belajar public speaking dan digital marketing bisa dilakukan oleh siapa saja terlebih oleh para milenial yang ingin mengembangakan keahlian, keterampilan serta pengembangan diri. Termasuk sebuah komunitas. Sebuah komunitas yang baik harus mampu meningkatkan kemampuan, kemandirian sumber daya yang ada, yaitu dimana sebuah komonitas harus mampu menghasilkan sebuah terobosan baik bagi anggotanya, maupun bagi kelompok komunitas tersebut. Komunitasnya harus mampu menghasilkan keuntungan baik berupa finansial maupun non finansial. Keuntungan finansial harus diawali usaha atau bisnis walau secara kecil-kecilan. Hal itulah yang mendorong kami untuk melakukan kegiatan pengabdian kepada masyarakat kepada komunitas ARIMBIN IX. Kegiatan ini bertujuan untuk memberikan pelatihan keterampilan anggota komunitas pencinta alam
\end{abstract}


tersebut agar mampu berkomunikasi dengan baik, mempunyai rasa percaya diri ketika tampil didepan umum serta memberikan pembekalan anggota komunitas pecinta alam untuk berwirausaha melalui digital marketing pada masa pandemic covid-19. Metode yang akan dipakai dalam pencapaian tujuan yaitu dengan berbagai metode seperti ceramah, diskusi, praktek dan tanya jawab, serta pendampingan bagi komunitas secara rutin. Program ini mempunyai hasil dan tujuan jangka panjang berdasarkan beberapa bentuk pengabdian yakni mewujudkan sebuah komunitas yang produktif baik bagi organisasi maupun anggotanya baik dimasa pandemic maupun dimasa yang akan datang.

\section{Kata Kunci: Public speaking, digital marketing, komunitas, pandemic, covid 19.}

\section{A. PENDAHULUAN}

Komunikasi yang tidak baik maka akan menghambat seseorang dalam mengembangkan karir maupun kemajuan sebuah organisasi/perusahaan. Untuk itu komunikasi sangat lah perlu baik untuk setiap orang maupun organisasi. Keahlian untuk berkomunikasi sebenarnya bisa dipelajari, baik secara otodidak maupun mengikuti pelatihanpelatihan public speaking yang semakin marak belakangan ini.

Setiap organisasi atau perusahaan pasti mempunyai tujuan baik, salah satunya adalah menjadikan pribadi anggota lebih baik lagi serta meningkatkan kesejahteraan anggota organisasi tersebut. Hal pertama yang bisa dilakukan memberikan keterampilan dan keahlian para anggotanya untuk selangkah lebih maju. Kegiatan seperti inilah yang dinamakan kegiatan pemgembangan diri. Pengembangan diri akan membuat kita memiliki kualitas diri yang lebih baik, terutama dalam kehidupan bermasyarakat dan bernegara. Pengembangan diri berarti suatu usaha individu dalam memenuhi kebutuhannya terhadap aktualisasi diri. Kebutuhan aktualisasi diri yaitu kebutuhan puncak atau tertinggi diantara kebutuhankebutuhan manusia.

Organisasi adalah sekumpulan orang yang berada di dalam suatu wadah guna mencapai tujuan bersama. Organisasi sudah menjadi bagian yang bisa dikatakan tak pernah lepas dari kehidupan sosial. Sejak manusia lahir sampai mati, organisasi selalu hadir. Misalnya, kita lahir dalam sebuah keluarga. Keluarga merupakan organisasi sosial. Proses kelahirn dibantu oleh bidan yang bertugas di rumah sakit. Rumah sakit merupakan oranisasi sosial di bidang kesehatan. Begitulah seterusnya organisasi menjadi bagian dari hidup kita. Organisasi juga terdiridari dua golongan yaitu organisasi resmi dan organisasi tidak resmi.

Komunitas adalah suatu kelompok sosial yang menyatukan diri terdiri dari beberapa orang yang mempunyai kesamaan dalam hal kebutuhan, kepercayaan, bakat, minat dan hobi sehingga menciptakan rasa nyaman dari setiap anggota kemunitas tersebut. Dalam Hermawan (2008) menjelaskan bahwa Komunitas adalah sekelompok orang yang saling peduli satu sama lain lebih dari yang seharusnya, dimana dalam sebuah komunitas terjadi relasi pribadi yang erat antar para anggota komunitas tersebut karena adanya kesamaan interest dan values. Untuk daerah perkotaan yang sudah sangat padat dengan kegiatan yang berhubungan pekerjaan, kemunculan komuitas hobi ini menjadi hal yang menarik untuk diminati.

Salah satu tujuan dari komunitas/organisasi diatas adalah meningkatkan kemampuan, kemandirian dan sumber daya yang ada, yaitu dimana sebuah organisasi harus mampu menghasilkan sebuah terobosan baik bagi anggotanya, maupun bagi kelompok organisasi tersebut. Sumber daya harus mampu di olah sedemikian rupa sehingga menjadi asset 
berharga bagi organisasi. Sumber daya manusia harus menjadi SDM yang unggul, berkarakteristik, serta mempunyai keterampilan yang bagus. Organisainya harus mampu menghasilkan keuntungan baik berupa finansial maupun non finansial. Keuntungan finansial harus diawali usaha atau bisnis walau secara kecil-kecilan.

Salah satu komunitas yang berada di Kota Tangerang Selatan adalah Komunitas Anak Rimba Bintaro IX "ARIMBIN IX". Komunitas tersebut mempunyai tujuan yaitu sebagai wadah pembinaan kepada generasi muda yang berminat dengan kegiatan alam, meningkatkan kepedulian, kecintaan terhadap lingkungan, serta meningkatkan kebersamaan dan persaudaraan sesama anggota dan masyarakat. Komunitas ARIMBIN IX juga mempunyai tujuan bersama yaitu ingin bersama-sama turut mensejahterakan anggota khususnya dan masyarakat pada umumnya.

Dalam masa pandemi seperti sekarang ini komunitas tersebut sangat kurang produktif, kegiatan alam tidak lagi berjalan, acara kumpul-kumpul seperti bakti sosial sebagai wujud kepedulian terhadap sesama anggota dan masyarakat berkurang bahkan untuk sementara vakum. Untuk itu sebagai komunitas sudah selayaknya bergerak cepat mengatur kembali langkah yang akan ditempuh agar tetap produktif walau mengahadapi situasi semacam ini.

Salah satu cara yang bisa diambil komunitas pada masa pandemic sekarang ini adalah yaitu meningkatkan kompetensi diri sebagai makhluk sosial yang terus berinteraksi dengan sesama, maka dari itu sebagai anggota komunitas sangat perlu mempunyai keterampilan, yaitu salah satunya adalah keterampilan berkomunikasi. Selain itu untuk mensejahterkana anggota maupun masyarakat disekitarnya, anggota komunitas harus mempunyai kegiatan yang dapat meningkatkan taraf hidup secara pribadi maupun secara berkelompok.

Untuk itu kami merasa tergerak untuk melakukan kegiatan Pengabdian kepada Masyarakat kepada komonitas tersebut, dengan tujuan meningkatkan kompetensi para anggota pecinta alam tesebut melalui Pelatihan Public Speaking dan Digital Marketing pada Komunitas Pecinta Alam "ARIMBIN IX" atau Anak Rimba Bintaro IX yang beralamat di Jalan H. Som Rt 005 Rw 01 Kelurahan Pondok Pucung, Kecamatan Pondok Aren, Tangerang Selatan, Baten. Dimana pelatihan public speaking dan pelatihan digital marketing tersebut adalah sebagai sarana untuk mempersiapkan para anggota komunitas agar mempunyai kemampuan berbicara yang baik didepan umum, mempunyai rasa percaya diri yang tinggi serta dapat memanfaatkan digital marketing sebagai upaya merintis bisnis atau berwirausaha pada masa pandemic covid-19.

\section{B. METODE PELAKSANAAN}

Adapun metode pelaksanaan kegiatan secara lengkap disajikan melalui penjelasan berikut dibawah ini:

1. Survei Tempat Pelaksanaan Kegiatan

Kegiatan ini dimaksudkan untuk menggali informasi tentang kondisi geografis dan kondisi masyarakat didaerah tempat kegiatan. Informasi tersebut berupa lokasi, permasalahan yang dihadapi dalam pada lokasi tersebut

2. Persiapan Sarana dan Prasarana.

Kegiatan ini dimaksudkan untuk merencanakan kebutuhan baik sarana dan prasarana yang akan digunakan dalam pelaksanaan kegiatan dengan tetap memperhatikan kebutuhan masyarakat secara umum dan khusus demi tercapainya target pengabdian kepada masyarakat. Sarana dan prasarana yang dimaksud berupa projektor, spanduk daln lain-lain. 
3. Pelaksanaan Kegiatan.

Kegiatan yang dilakukan adalah berupa pelatihan atau penyuluhan dalam bentuk pertemuan secara langsung dengan masyarakat serta anggota komunitas ARIMBIN IX (Anak Rimba Bintaro Sektor 9) di Jl. Som RT 005 RW 01, Kelurahan Pondok Pucung, Kecamatan Pondok Aren, Tangerang Selatan, Banten, pada hari Sabtu dan Minggu 7 - 8 November 2020.

Untuk pelaksanaan kegiatan tersebut, maka digunakan beberapa metode pelatihan, yaitu:

a. Metode Ceramah.Metode ceramah dipilih untuk memberikan penjelasan mengenai public speaking dan digital marketing.

b. Metode Tanya Jawab.Metode tanya jawab ini dipilih karena sangat penting bagi para peserta pelatihan yaitu mengenai bagaimana cara meningkatkan keahlian dalam public speaking dan digital marketing

c. Metode Simulasi/praktek. Metode simulasi/praktek ini diberikan kepada para peserta pelatihan untuk mempraktekkan berbicara didepan umum dan mempraktekkan keterampilan dalam pemasaran online.

4. Monitoring dan Evaluasi.

Kegiatan ini dimaksudkan untuk meninjau perkembangan aktualisasi anggota komunitas dan masyarakat terhadap kegiatan yang telah dilakukan sebelumnya dengan harapan dapat dilaksanakan sesuai dengan teori yang telah di peroleh melalui kegiatan yang telah dilaksanakan. Evaluasi juga bertujuan untuk memahami pola pemahaman anggota dan masyrakat terhadap informasi atau pengetahuan baru yang diperoleh dari pelaksana kegiatan. Hasil ini diharapkan mampu menjadi dasar pengembangan diri yaitu menjadi anggota komunitas yang produktif dan inovatif yaitu mempunyai bekal komunikasi yang baik dan keterampilan digital marketing guna meningkatkan penghasilan di masa pandemic maupun dimasa yang akan datang.

5. Tahap Pelaporan Hasil Pengabdian.

Pada tahan pelaporan hasil pengabdian kepada masyarakat ini merupakan laporan serangkaian kegiatan mulai dari survey pra-pengabdian hingga pelaporan kegiatan.

6. Tahap Publikasi.

Hasil atau laporan kegiatan pengabdian kepada masyarakat akan dipublikasikan sebagai luaran dari kegiatan pengabdian kepada masyarakat ini.

\section{HASIL DAN PEMBAHASAN}

Peserta yang hadir sebanyak 50 orang, 25 anggota komunitas, tokoh masyarakat yang terdiri dari perwakilan perangkat RT, serta para dosen dan mahasiswa Universitas Pamulang. Kegiatan dilaksanakan melalui ceramah, diskusi tanya jawab, serta beberapa contoh kasus yang terjadi dalam permasalahan komunikasi dalam organisasi serta contoh permasalahan pemasaran disekitar kita. Selain itu para narasumber juga memberikan penyuluhan dan pelatihan yang diikuti oleh para peserta yang kumpul di Mushola Darul Mubin.

Hasil penelitian Emploeyment Research Institute (2005) mengungkapkan bahwa kesuksesan seseorang 18\% dikarenakan mempunyai hard skill, dan 82\% dikarenakan seseorang mempunyai soft skill. Yang termasuk soft skill salah satunya adalah komunikasi. Selain itu terbukti faktor penunjang kesuksesan seperti network atau jaringan bisa kita miliki jika kita dikenal oleh banyak orang karena memiliki komunikasi yang baik.

Jadi keterampilan berkomunikasi yang baik atau dikenal dengan public speaking memang merupakan kebutuhan semua orang dan semua profesi, baik sebagai siswa dan 
mahasiswa, seorang supervisior atau manager, seorang tokoh agama atau tokoh masyarakat, pengacara, dokter, guru atau dosen, tenaga marketing dan lain sebagainya.

Selain komunikasi yang baik, penggunaan teknologi digital berupa media sosial merupakan sarana marketing yang saat ini sangat tepat digunakan dimasa pandemic seperti ini. Penggunaan media sosial diharapkan dapat digunakan sebagai salah satu ide kreatif anak muda untuk memulai bisnis online membuka peluang baru sehingga anak muda tidak lagi seratus persen mengandalkan orang tua, tetapi mulai berpenghasilan sendiri. Dengan bisnis melaui media sosial memungkinkan semakin banyak calon wirausahawan yang akan muncul dan turut meningkatkan perekonomian di sekitar kita terlebih banyak orang yang kehilangan pekerjaan akibat pandemic covid-19.

Memulai bisnis online tidaklah memelukan biaya yang besar. Bisnis online bisa menggunakan biaya promosi yang sangat minim tetapi memperoleh hasil yang maksimal yaitu menggunakan Facebook ads, Google Adwords maupun google Search. Atau dengan biaya nol persen tetapi keuntungan yang bagus yaitu menggunakan Website, Instagram, Youtubee, Facebook, Twiteer, Line, Whatsapp, Tiktok atau akun-akun yang lain yang dikelola. Selain model promosi atau penjualan melalu media sosial untuk memaksimalkan pemasaran, kita juga bisa melalui market place yang ada saaat ini seperti, Buka lapak, Tokopedia, Shoope, Lazada, Blibli, JD.id. dan lain sebagainya.

Dengan diadakan pelatihan public speaking dan digital marketing diharapkan kita bisa melakukan promosi dengan Bahasa yang baik dan benar melalui media sosial. Peserta pengabdian nantinya dituntut lebih aktif dalam berkominikasi dan aktif dalam mengelola akun-akun media sosialnya agar produk yang akan dijual mampu bersaing di pasar online.

Selain itu, setelah mengikuti pelatihan dan kegiatan ini ini diharapkan bahwa peserta akan mampu:

1. Peserta mampu membentuk mindset tentang pentingnya public speaking dalam organisasi dan masyarakat.

2. Peserta mampu merencanakan dan menyusun materi presentasi dengan baik.

3. Peserta mampu melakukan public speaking dengan percaya diri, menarik serta mengesankan tanpa mengurangi pesan yang disampaikan.

4. Peserta memahami digital marketing dan dapat mengaplikasikannya sehingga dapat meningkatkan pemasukan baik pribadi dan organisasi.

5. Peserta mampu menciptakan digital branding dengan cost yang lebih efisien.

6. Peserta mampu menentukan model dasar pelaksanaan digital marketing yang dapat dijalankan sesuai dengan kondisi saa ini.

7. Peserta mampu menyusun strategi penggunaan Media Online, berdasarkan tujuan dan kategori produk.

8. Peserta memahami kelebihan dan kekurangan berbagai jenis media

\section{KESIMPULAN DAN SARAN}

\section{Kesimpulan}

Hasil kegiatan PkM pada komunitas Anak Rimba Bintaro Sektor 9 (ARIMBIN IX) berjalan dengan lancar. Pelatihan public speaking dan digital marketing memberikan kemudahan anggota komunitas dalam melakukan kegiatan yang positif dimasa pandemic yaitu memulai bisnis dengan didasari komunikasi yang baik melalui digital marketing, sehingga komunitas lebih produktif dimasa sekarang maupun masa yang akan datang. 
Saran

Berikut adalah beberapa saran yang ditujukan untuk komunitas Anak Rimba Bintaro Sektor 9 (ARIMBIN IX) dalam meningkatkan produktifitas dimasa pandemic baik bagi organisasi maupun anggota komunitas:

1. Selalu berlatih berkomunikasi dan selalu percaya diri untuk berbicara didepan umum.

2. Mulai membuat akun media sosial yang terpisah dari akun pribadi untuk memulai bisnis online.

3. Belajar menciptakan digital branding dan mulai menentukan model dasar pelaksanaan digital marketing dengan cost yang lebih efisien dan sesuai dengan kondisi saat ini

4. Selalu aktif dimedia sosial dengan terus menawarkan produk produk yang kita jual sebagai strategi pemasaran.

\section{DAFTAR PUSTAKA}

Abdullah, Thamrin dan Tantri, Francis. 2016. Manajemen Pemasaran. Cetakan kelima. Jakarta. Penerbit PT. Rajagrafindo Persada.

Alma, 2013, Manajemen Pemasaran Dan Pemasaran Jasa, CV Alfabeta, Bandung.

Ariyanto, Aris 2019, The Influence of Price and Service Quality on Customer Satisfaction at PT Sarana Estate

Ariyanto, A., Sudarsono, A., Ivantan, I., Akbar, M. F., \& Munarsih, M. (2020). Pengembangan Potensi Destinasi Wisata Curug Angkrek melalui Media Sosial di Kp. Cimuncang, Desa Karangnunggal, Kabupaten Tasikmalaya Jawa Barat. BAKTIMAS: Jurnal Pengabdian pada Masyarakat, 2(2), 95-99.

Kotler dan Amstrong, 2012, Prinsip-Prinsip Pemasaran Jilid I. Erlangga, Jakarta.

, Philip. et. al. 2020. Marketing 4.0 Bergerak dari Tradisional ke Digital. Cetakan kelima. Jakarta. Penerbit PT. Gramedia Pustaka Utama.

Dan Keller, 2012, Manajemen Pemasaran, Edisi 12, Penerjemah Benyamin Molan, Indeks, Jakarta.

Mamang, Etta Sangadji dan Sopiah. Perilaku Konsumen. 2013. Edisi satu. Yogyakarta. Penerbit CV. Andi Offset.

Munarsih, M., Akbar, M. F., Ariyanto, A., Ivantan, I., \& Sudarsono, A. (2020). Pelatihan Digital Marketing Dalam Meningkatkan Kompetensi Siswa Untuk Berwirausaha Pada Smk Muhammadiyah Parung-Bogor. Jurnal Pengabdian Dharma Laksana, 3(1), 22-28.

Rangkuty, 2009, Riset Pemasaran, Gramedia pustaka Utama, Jakarta.

Rulli Nasrullah, 2016, Media Sosial Perspektif Komunikasi, Budaya, Sosioteknologi, Cet.kedua, Simbiosa Rekatama Media, Bandung

Stelzner, MA (2012). Social Media Marketing Industry Report. How Marketers Are Using Social Media to Grow Their Business

Stockdale, Ahmed, \& Scheepers. (2012). Identifying Business Value from The Use of Social Media: An SME Perspective. Pacific Asia Conference on Information Systems. Association for Inforamtion System Electronic Library

Swastha dan Irawan, 2011, Pemasaran Modern, Liberty, Yogyakarta. 
P-ISSN 2716-3652 E-ISSN 2723-1003

DEDIKASI PKM UNPAM

Vol. 2, No. 1, Januari 2021, Hal (68-74)

@Prodi Manajemen Fakultas Ekonomi Universitas Pamulang

, Basu Dharmamesta dan Hani, T Handoko. 2018. Manajemen Pemasaran Analisis Perilaku Konsumen. Edisi Pertama. Cetakan ketujuh. Yogyakarta. Penerbit BPFE. 